\title{
РОЛЬ СУДЕБНОЙ ПРАКТИКИ В СОЗДАНИИ НОВЫХ НОРМ ПРАВА ДОГОВОРОВ ВЕЛИКОБРИТАНИИ
}

\section{THE ROLE OF JUDICIAL PRACTICE IN THE CREATION OF THE NEW RULES OF ENGLISH CONTRACT LAW}

A. Kozlov

Summary: This article analyzes in detail the role of courts in the reform of English contract law. The author identifies five levels of influence of the judicial system on the transformation of British national law. Each level is disclosed on the basis of specific examples from judicial practice. The conclusion is made about the fact that British judicial system can exercise a full-fledged legislative function, which allows implementation of legal reforms of any complexity and scope.

Keywords: english contract law, courts, precedent, legal principle, standard of proof, legal doctrine, legal term.

\author{
Козлов Антон Гордеевич \\ Преподаватель, ФГБОУВО «Государственный \\ университет управления», г. Москва \\ antonkozlov3000@yandex.ru
}

Аннотация: В данной статье подробно анализируется роль деятельности судов в реформировании норм права договоров Великобритании. Автор выделяет пять уровней влияния судебной системы на трансформацию национального права Великобритании. Каждый уровень раскрывается на конкретных примерах из судебной практики. Сделан вывод о наличии у судебной системы Великобритании полноценной законодательной функции, позволяющей осуществлять правовые реформы любой сложности и объема.

Ключевые слова: право договоров Великобритании, суды, прецедент, правовой принцип, стандарт доказывания, правовая доктрина, правовой термин.

ми; 3) на уровне утверждения стандартов доказывания как объективных критериев установления фактов в судебных спорах; 4) на уровне разработки правовых доктрин, положения которых действуют при наличии пробела в законодательстве (здесь судьи действуют наравне с учеными-правоведами); 5) на уровне формулирования правовых дефиниций и терминов - слов и словосочетаний, обозначающих правовые понятия. Вышеописанные пять уровней будут рассмотрены в данной статье на конкретных примерах из права договоров Великобритании, являющегося одной из основных отраслей материального права страны, законодательство которой оказало огромное влияние на формирование англосаксонской правовой семьи.

1) Один из ключевых принципов права договоров Великобритании - принцип свободы договора- был сформулирован судьями и в настоящее время трансформируется при непосредственном участии судов, действующих в качестве субъектов законодательной власти. Данный принцип был сформулирован в XIX веке и первоначально подразумевал практически полную свободу субъектов гражданского права при осуществлении ими своих частных интересов. Суды фактически узаконили возможность заключать сделки на любых условиях при наличии согласия сторон. Сделано это было в целях «развития национальной торговли» («furtherance of national trade») и в полном соответствии с «принципом невмешательства» («laissez-faire») - экономической доктриной, господствовавшей в буржуазных странах того времени. Экстраполируя основные положения данной доктрины на юриди- 
ческую почву, судьи установили презумпцию разумного поведения участников экономического оборота, согласно которой ни одно частное лицо (и уж тем более лицо, профессионально занимающееся торговлей) не станет по своей воле заключать соглашение, условия которого вредят его частным интересам или как-либо препятствуют их осуществлению. [1] Существовало только два исключения из вышеописанного правила - сделки, прямо нарушающие нормы закона, и, следовательно, противоречащие юридической воле Короны, парламента и судов (obviously illegal deals), а также сделки, противоречащие нормам нравственности, и, следовательно, идущие вразрез с политической волей Церкви (immoral deals). [2]

B XX веке развитие системы международного частного права и появление международных и наднациональных политико-правовых институтов (таких как Организация Объединенных Наций и Европейский Союз) потребовали внесения следующих существенных изменений в понимание принципа свободы договора: а) вследствие того, что у судов Соединенного Королевства появилась обязанность рассматривать международные гражданско-правовые споры в случае, когда стороны указывают в договоре на то, что все условия сделки регулируются правом Великобритании, судебная практика с течением времени разработала особые правила, определившие особенности интерпретации текстов договоров судьями: представители судебной власти, анализируя формулировки конкретных юридических документов, ограничены определением «первоначальных намерений» сторон («original intentions of the parties»), послуживших причиной для их добровольного согласия на заключение сделки; б) вступление Великобритании в Европейский Союз в 1973 году потребовало привести положения права договоров Соединенного Королевства в соответствие с гражданско-правовыми стандартами, действующими в границах «единой Европы», в результате чего судьи были вынуждены ужесточить условия вступления в сделки, а также правила составления ряда договоров: в частности, была определена категория публичных договоров, которые лица, осуществляющие предпринимательскую деятельность, обязаны заключать с любым желающим, а также были признаны незаконными так называемые «дискриминационные» основания для отказа в заключении соглашений с физическими лицами вследствие их принадлежности к определенной политической или религиозной организации, их убеждений, мнений и т.д. [6]

2) Судьи внесли огромный вклад в создание юридической конструкции договора, используемой в национальном праве Великобритании. В результате накопления судебной практики по вопросам разрешения гражданско-правовых споров было установлено, что каждый договор, признаваемый действительным, должен соответствовать следующим требованиям: а) в договоре должно быть отражено согласие сторон на его заключение, а именно безоговорочный и безусловный акцепт оферты; б) из текста договора должно быть очевидным намерение сторон связать себя взаимными обязательствами и получить взаимные права; в) по условиям договора каждая из сторон должна предоставить в пользование своему контрагенту что-либо, имеющее ценность в глазах закона (передать товар, оказать услугу, оплатить предоставленные товар или услугу и т.д.); г) договор должен быть заключен в форме, предусмотренной законом для совершения сделок данного вида; д) условия договора не должны противоречить законам Великобритании. Следует особо отметить, что недействительность договора лишает стороны права обращения в суд при его нарушении. [3]

3) При рассмотрении гражданско-правовых споров между юридическими лицами судьи применяют так называемый «стандарт должной осмотрительности» («due diligence standard»), призванный определить степень разумности поведения сторон, регулярно вступающих в экономические отношения на профессиональной основе. Каждая сторона таких сделок по умолчанию признается действовавшей «с должной осмотрительностью», т. е. изучившей всю доступную информацию о финансовом положении своего контрагента и истории его прошлых сделок. В случае, если контрагент оказывается неплатежеспособным (например, не может оплатить партию доставленных ему товаров) и при этом истец не может доказать, что действовал с должной осмотрительностью, суд вправе отказать лицу, обратившемуся за защитой своих прав, в реституции. [7]

4) В конце 70х гг. XX века в судах Великобритании стали часто рассматриваться гражданско-правовые споры между юридическими лицами, причиной которых явилась так называемая «борьба типовых договоров» («battle of standard forms»). Каждая из сторон во время переговоров отправляла своему контрагенту список стандартных условий, на которых она обычно заключает соглашения в процессе осуществления своей профессиональной деятельности. Нередко содержание подобных списков выявляло явное и существенное противоречие между намерениями сторон. Складывалась безвыходная ситуация: каждая из сторон была готова заключить сделку, но исключительно на собственных условиях. Для разрешения этой ситуации суды, фактически действуя в роли, более привычной для ученых-правоведов, разработали так называемую доктрину «последнего слова» («last shot doctrine»), в соответствии с которой документом, определяющим окончательные условия будущей сделки, является последний по времени отправки типовой договор. Контрагент стороны, отправившей такой договор обязан или безоговорочно принять содержащиеся в нем условия, или полностью отказаться от заключения сделки. [4] 
5) Многие прецедентные решения содержат новые дефиниции и термины, вводимые судьями в целях объяснения и обозначения конкретных правовых реалий. Так, в одном из первых прецедентных решений по делу о защите прав потребителей Carlill v. Carbolic Smoke Ball Со. (1893) суд постановил, что в сопроводительном описании товара, предложенного для продажи в магазине, может содержаться информация, «направленная исключительно на привлечение внимания потенциального покупателя и не отражающая реальных характеристик товара». Информация подобного рода причисляется судьями к категории «маркетинговых уловок» («mere marketing puffs») и не является юридически значимой. [5]

Таким образом, на основании конкретных примеров, рассмотренных выше, можно сделать вывод о том, что судебная практика стран англосаксонской правовой семьи является полноценным источником законодательных инициатив, так как прецедентные дела могут заключать в себе правовые реформы любого уровня и объема - от формулирования новых руководящих принципов отрасли права до включения в профессиональную юридическую лексику новых дефиниций и терминов.

\section{ЛИТЕРАТУРА}

1. Козлов А.Г. Professional English: International private law [Профессиональный английский язык: международное частное право]/000 «РУСАЙНС», 2019. $118 \mathrm{c}$.

2. Andrew Burrows. A Restatement of the English Law of Contract [Пересмотр права договоров Великобритании]/0xford University Press; 1st edition, 2016. $297 \mathrm{p}$.

3. Ewan McKendrick. Contract law [Право договоров]/Red Globe Press; 13th edition, 2019. - $476 \mathrm{p}$.

4. John Cartwright. Contract law: An Introduction to the English Law of Contract for the Civil Lawyer [Право договоров: Введение в право договоров Великобритании для адвоката по гражданским делам]/Hart Publishing; 1st edition, 2016. - 513 p.

5. Joseph Chitty and others. Chitty on Contracts: General Principles [Читти о договорах: общие принципы]/Sweet and Maxwell; 33rd edition, 2018. - 2561 p.

6. Paul Craig, Grainne De Burca. EU Law: Text, Cases and Materials [Право Европейского союза: текст, дела и материалы]/0xford University Press; 7th edition, 2020. - 1219p.

7. Richard Schaffer, Filiberto Agusti, Lucien J. Dhooge. International Business Law and Its Environment [Международное предпринимательское право и условия его развития]/Cengage Learning, 10th edition, 2017. - $696 \mathrm{p}$.

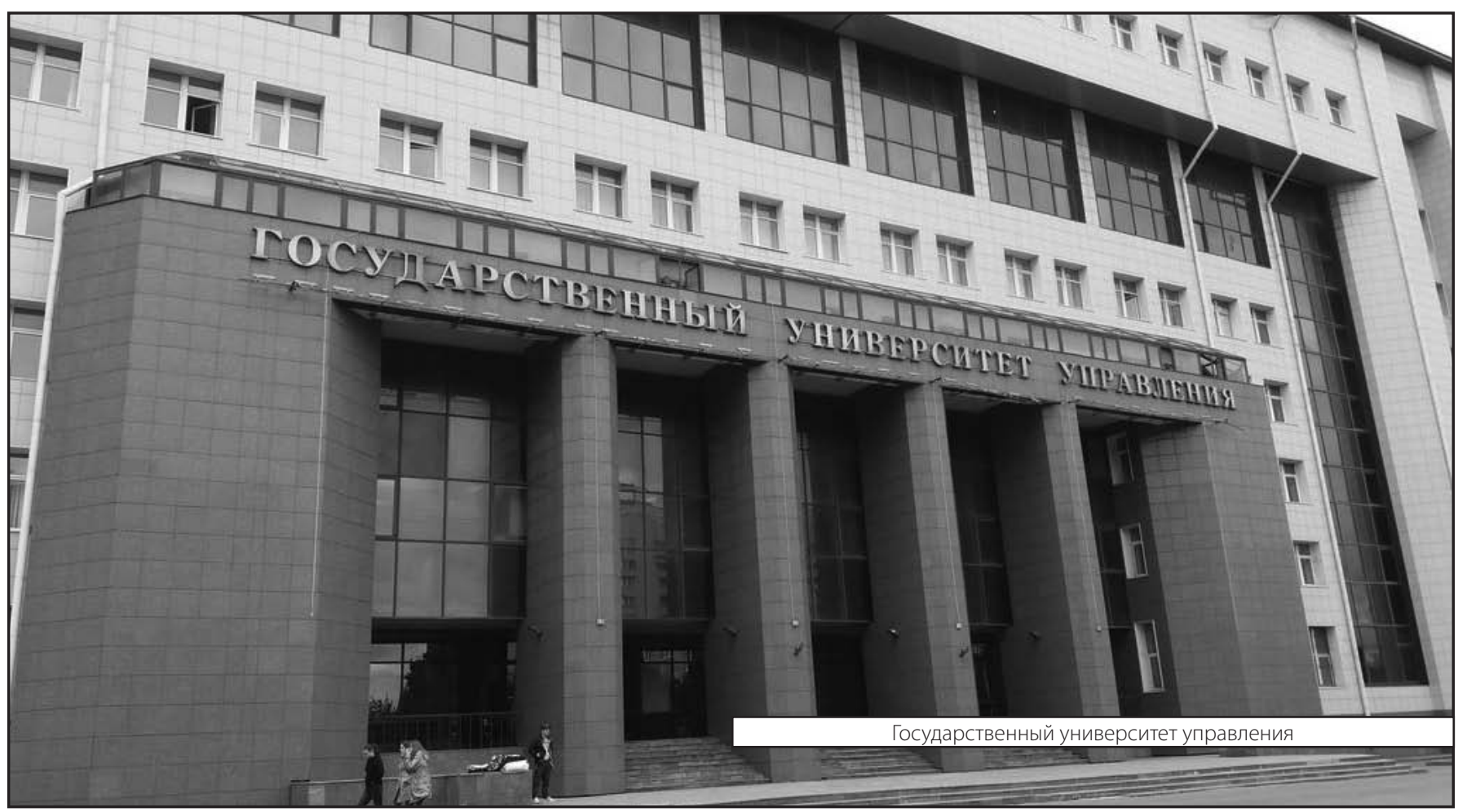

